\section{JURNAL EKONOMI EFEKTIF}

ISSN : $2622-8882$, E-ISSN : 2622-9935

Jurnal Ekonomi Efektif, Vol. 4, No. 1, Oktober 2021 @Prodi Manajemen Fakultas Ekonomi Universitas

Pamulang

\title{
ANALISIS PENGARUH CURENT RATIO TERHADAP RETURN ON ASSET PADA PT MAYORA, TBK PERIODE 2011-2020
}

\author{
Fatra Syahlan \\ STKIP PGRI Sukabumi, Sukabumi, Jawa Barat, Indonesia \\ fatrasyahlan@stkippgrisukabumi.ac.id
}

Manuskrip: September -2021; Ditinjau: September: -2021; Diterima: September-2021; Online: Oktober-2021; Diterbitkan: Oktober-2021

\begin{abstract}
ABSTRAK
Penelitian ini bertujuan untuk mengetahui pengaruh Curent Ratio terhadap Return On Asset pada PT. Mayora, Tbk Periode 2011-2020 . Metode yang digunakan adalah explanatory research. Teknik analisis menggunakan analisis statistik dengan pengujian regresi, korelasi, determinasi dan uji hipotesis. Hasil penelitian ini variabel Curent Ratio diperoleh nilai ratarata sebesar 234,38\%. Variabel Return On Asset diperoleh nilai rata-rata 8,40\%. Curent Ratio berpengaruh positif dan signifikan terhadap Return On Asset dengan nilai persamaan regresi Y $=-8,392+0,072 \mathrm{X}$, dan nilai koefisien korelasi 0,703 atau memiliki tingkat hubungan yang kuat dengan nilai determinasi sebesar 49,4\%. Uji hipotesis diperoleh signifikansi 0,014 <0,05.
\end{abstract}

\section{Kata Kunci: Curent Ratio , Return On Asset}

\begin{abstract}
This study aims to determine the effect of Curent Ratio on Return On Assets at PT. Mayora, Tbk Period 2011-2020. The method used is explanatory research. The analysis technique uses statistical analysis with regression, correlation, determination and hypothesis testing. The results of this study the Curent Ratio variable obtained an average value of 234.38\%. The Return On Assets variable obtained an average value of $8.40 \%$. Curent Ratio has a positive and significant effect on Return On Assets with a regression equation value of $Y$ $=-8.392+0.072 X$, and a correlation coefficient value of 0.703 or has a strong relationship with a determination value of $49.4 \%$. Hypothesis testing obtained a significance of 0.014 $<0.05$.
\end{abstract}

Keywords: Current Ratio, Return On Assets 


\section{PENDAHULUAN}

\section{A. Latar Belakang}

Mengikuti perubahan ekonomi yang tidak pasti dan pergerakannya sangat cepat. Sebuah investasi ke perusahaan-perusahaan yang sudah go public menjadi daya tarik terkini untuk masyarakat umum, return yang lebih besar daripada pemodalan di perbankan yang menjadi magnet para investor (Hartono, 2017). Kemudahan dalam menyalurkan dana dalam berinvestasi dianggap bisa memberikan nilai tabah terhadap apa yang sudah diinvestasikan. Persaingan usaha sangat ketat yang mengharuskan perusahaan menyediakan saranan dan sistem penilaian kerja yang dapat meningkatkan efisiensi dan daya saing, untuk menghadapi berbagai keadaan perekonomian yang terjadi saat ini.

Berinvestasi adalah sebuah keputusan yang harus diambil secara hati-hati, dengan harapan return maksimal dan risiko minimal, kehati-hatian dalam memperediksi dan memperoleh informasi yang menjadi bahan pertimbangan dalam menilai kinerja keuangan untuk memperoleh keputusan final para investor menanamkan modalnya.

PT. Mayora Indah, Tbk merupakan kelompok bisnis yang memproduksi makanan terkemuka di Indonesia.Terbukti bahwa Mayora Indah telah menghasilkan berbagai produk berkualitas yang saat ini menjadi merek-merek terkenal di dunia, seperti Kopiko, Danisa, Astor, Energen, Torabika dan lain-lain.

PT. Mayora Indah, Tbk harus tetap stabil. Itulah sebabnya analisis rasio keuangan perlu dilakukan agar kita dapat mengetahui gambaran posisi keuangan dari perusahaan tersebut. Bagi para pengguna laporan keuangan, mengetahui posisi keuangan suatu perusahaan adalah hal yang sangat penting karena pada dasarnya akan menjadi bahan pertimbangan dalam menentukan keputusan. Keuntungan atau laba yang diperoleh merupakan salah satu gambaran tentang kondisi keuangan suatu perusahaan. Laba yang dihasilkan oleh perusahaan dapat diketahui melalui alat pengukuran analisis laporan keuangan, analisis keuangan ini dilakukan agar para pengguna infomasi keuangan dapat mengetahui baik buruknya keadaan keuangan suatu perusahaan yang mencerminkan prestasi kerja dalam periode tertentu. Penggunaan informasi keuangan akan memudahkan investor akan menghitung rasio-rasio keuangannya yang mencakup rasio likuiditas, solvabilitas, aktivitas dan profitabilitas perusahaan untuk dasar pertimbangan dalam keputusan investasi.

Likuiditas menggambarkan kemampuan suatu perusahaan untuk memenuhi kewajiban finansialnya yang segera harus dipenuhi. Likuiditas akan mempengaruhi besar kecilnya dividen yang dibayarkan kepada para pemegang saham. Penelitian ini menggunakan rasio likuiditas yang diwakili oleh current ratio yaitu rasio yang menggambarkan kemampuan perusahaan untuk membayar utang yang harus dipenuhi dengan kas yang tersedia dalam perusahaan.

Untuk mengetahui seberapa besar perusahaan membayar utangnya dapat Dengan menggunakan lebih banyak hutang berarti memperbesar resiko yang ditanggung perusahaan. Begitu juga sebaliknya, dengan menggunakan lebih banyak hutang juga memperbesar tingkat pengembalian diharapkan debt to asset ratio adalah Ratio untuk mengukur mengenai besar aktiva perusahaan yang dibiayai dengan hutang (Kasmir 2013:158).

Berikut ini perkembangan Curent Ratio (dan Return On Asset PT Mayora, Tbk, Periode 2011-2020 sebagai berikut: 
Tabel 1. Perkembangan Curent Ratio s (CR) dan Return On Asset (ROA)

PT. Mayora, Tbk, Periode 2011-2020

\begin{tabular}{|c|c|c|}
\hline Tahun & Curent Ratio (CR) (\%) & Return On Asset (ROA) (\%) \\
\hline 2011 & $238,82 \%$ & $7,23 \%$ \\
\hline 2012 & $231,44 \%$ & $7,75 \%$ \\
\hline 2013 & $224,31 \%$ & $8,94 \%$ \\
\hline 2014 & $258,51 \%$ & $9,56 \%$ \\
\hline 2015 & $216,64 \%$ & $6,55 \%$ \\
\hline 2016 & $239,73 \%$ & $8,28 \%$ \\
\hline 2017 & $211,53 \%$ & $6,33 \%$ \\
\hline 2018 & $242,37 \%$ & $9,41 \%$ \\
\hline 2019 & $237,84 \%$ & $10,52 \%$ \\
\hline 2020 & $242,68 \%$ & $9,52 \%$ \\
\hline Rata-rata & $234,39 \%$ & $8,41 \%$ \\
\hline
\end{tabular}

Berdasarkan data pada tabel di atas, menunjukkan bahwa sepanjang tahun 20112020 pertumbuhan kemampuan perusahaan dalam membayar hutang jangka pendeknya secara keseluruhan Curent Ratio rata-rata mengalami perkembangan yang fluktuatif. Persentase pencapaian Curent Ratio tertinggi terjadi pada tahun 2014 yang mencapai sebesar 258,51\%, sedangkan persentase pencapaian terendah terjadi pada tahun 2017 yang hanya mencapai $211,53 \%$. Secara rata-rata dicapai $234,39 \%$ per tahunnya.

Kondisi serupa juga terjadi pada persentase pencapaian Return On Asset yang perkembangannya dari tahun ke tahun mengalami hal yang serupa. Persentase Return On Asset tertinggi terjadi pada tahun 2019 yakni sebesar 10,52\% dan Return On Asset terendah terjadi pada tahun 2017 sebesar 6,33\%. Secara rata-rata dicapai 8,41\%.

Salah satu tujuan didirikannya perusahaan adalah untuk memperoleh laba (profit), jika perusahaan mempunyai laba yang tinggi maka akan meningkatkan daya saing perusahaannya dan melakukan peningkatan aktivitas ekonomi dan pertumbuhan dalam dunia usaha sehingga dapat membuka kesempatan untuk investasi yang baru. Profitabilitas mengukur tingkat keuntungan yang dihasilkan oleh perusahaan. Di samping bertujuan untuk mengetahui kemampuan perusahaan dalam menghasilkan laba selama periode tertentu, rasio ini juga bertujuan untuk mengukur tingkat efektifitas manajemen dalam menjalankan operasional perusahaan (Hery, 2016).

Menurut Munawir (2016), definisi profitabilitas adalah sebagai berikut "Profitabilitas adalah menunjukkan kemampuan perusahaan untuk menghasilkan laba selama periode tertentu Rentabilitas suatu perusahaan diukur dengan kesuksesan perusahaan dan kemampuan menggunakan aktivanya secara produktif, dengan demikian rentabilitas suatu perusahaan dapat diketahui dengan memperbandingkan antara laba yang diperoleh dalam suatu periode dengan jumlah aktiva atau jumlah modal perusahaan tersebut."Menurut Agus Sartono (2016) profitabilitas "Profitabilitas adalah kemampuan perusahaan dengan memperoleh laba dalam hubungannya dengan penjualan, total aktiva, maupun modal sendiri."

Berdasarkan latar belakang tersebut maka dalam pembahasan ini peneliti mengambil judul "Analisis Pengaruh Curent Ratio Terhadap Return On Asset Pada PT. Mayora, Tbk Periode 2011-2020”.

\section{B. Rumusan Masalah}

1. Bagaimana kondisi Curent Ratio pada PT. Mayora, Tbk ?.

2. Bagaimana kondisi Return On Asset pada PT. Mayora, Tbk ?.

3. Adakah pengaruh Curent Ratio terhadap Return On Asset pada PT. Mayora, Tbk?. 


\section{Tujuan Penelitian}

1. Untuk mengetahui kondisi Curent Ratio pada PT. Mayora, Tbk .

2. Untuk mengetahui kondisi Return On Asset pada PT. Mayora, Tbk .

3. Untuk mengetahui pengaruh Curent Ratio terhadap Return On Asset pada PT. Mayora, Tbk .

\section{METODE PENELITIAN}

\section{Populasi}

Populasi dalam penelitian ini laporan keuangan PT. Mayora, Tbk selama 10 tahun

\section{Sampel}

Teknik pengambilan sampling dalam penelitian ini adalah samplel jenuh, dimana semua anggota populasi dijadikan sebagai sampel. Dengan demikian sampel dalam penelitian ini laporan keuangan PT. Mayora, Tbk selama 10 tahun.

\section{Jenis Penelitian}

Jenis penelitian yang dipakai adalah kuantitatif, dimana tujuannya adalah untuk mengetahui mencari keterhubungan antara variabel independen terhadap variabel dependennya

\section{Metode Analisis Data}

Dalam menganalisis data digunakan analisis deskriptif, analisis regresi linier sederhana, koefisien korelasi, koefisien determinasi dan uji hipotesis.

\section{HASIL PENELITIAN}

\section{Analisis Deskriptif}

Pada pengujian ini digunakan untuk mengetahui skor minimum dan maksimum skor tertinggi, ratting score dan standar deviasi dari masing-masing variabel. Adapun hasilnya sebagai berikut:

Tabel 2. Hasil Analisis Descriptive Statistics

Descriptive Statistics

\begin{tabular}{lr|r|r|r|r} 
& \multicolumn{2}{c}{ Descriptive Statistics } & & \\
& N & Minimum & Maximum & \multicolumn{1}{c}{ Mean } & Std. Deviation \\
\hline CR & 10 & 211.53 & 258.51 & 234.387 & 13.833 \\
\hline ROA & 10 & 6.33 & 10.52 & 8.409 & 1.411 \\
\hline Valid N (listwise) & 10 & & & & \\
\hline
\end{tabular}

Curent Ratio diperoleh nilai minimum sebesar $211,53 \%$ dan nilai maximum $258,51 \%$ dengan rata-rata sebesar 234,38\% dengan standar deviasi $13,83 \%$.

Sedangkan nilai Return On Asset diperoleh nilai minimum sebesar 6,33\% dan nilai maximum 10,52\% dengan rata-rata sebesar 8,40\% dengan standar deviasi $1,411 \%$.

\section{Analisis Kuantitatif.}

Pada analisis ini dimaksudkan untuk mengetahui pengaruh variabel independen terhadap variabel dependen. Adapun hasil pengujian sebagai berikut:

\section{a. Analisis Regresi Linier Sederhana}

Uji regresi ini dimaksudkan untuk mengetahui perubahan variabel dependen jika variabel independen mengalami perubahan. Adapun hasil pengujiannya sebagai berikut:

Tabel 3. Hasil Pengujian Regresi Linier Sederhana Coefficients $^{\text {a }}$

\begin{tabular}{|c|c|c|c|c|c|c|}
\hline \multirow{2}{*}{\multicolumn{2}{|c|}{ Model }} & \multicolumn{2}{|c|}{ Unstandardized Coefficients } & \multirow{2}{*}{$\begin{array}{c}\text { Standardized Coefficients } \\
\text { Beta }\end{array}$} & \multirow[b]{2}{*}{$\mathrm{t}$} & \multirow[b]{2}{*}{ Sig. } \\
\hline & & B & Std. Error & & & \\
\hline 1 & (Constant) & -8.392 & 6.023 & & -1.393 & .201 \\
\hline & $\mathrm{CR}$ & .072 & .026 & .703 & 2.794 & .023 \\
\hline
\end{tabular}

a. Dependent Variable: EPS 
Berdasarkan hasil pengujian pada tabel di atas, diperoleh persamaan regresi $\mathrm{Y}$ $=-8,392+0,072 \mathrm{X}$. Dari persamaan tersebut dijelaskan sebagai berikut:

1) Konstanta sebesar $-8,392$ diartikan jika Curent Ratio tidak ada, maka telah terdapat nilai Return On Asset sebesar -8,392 point.

2) Koefisien regresi Curent Ratio sebesar 0,072 , angka ini positif artinya setiap ada peningkatan Curent Ratio sebesar 0,072 point maka Return On Asset juga akan mengalami perubahan sebesar 0,072 point.

\section{b. Analisis Koefisien Korelasi}

Analisis koefisien korelasi dimaksudkan untuk mengetahui tingkat kekuatan hubungan dari variabel independen terhadap variabel dependen. Adapun hasil pengujian sebagai berikut:

Tabel 4. Hasil Pengujian Koefisien Korelasi Curent Ratio Terhadap Return On Asset.

Correlations $^{\mathrm{b}}$

\begin{tabular}{llrrr} 
& & ROA & \multicolumn{2}{r}{ EPS } \\
\hline CR & Pearson Correlation & 1 & $.703^{*}$ \\
\cline { 2 - 4 } & Sig. (2-tailed) & & .023 \\
\hline \multirow{2}{*}{ ROA } & Pearson Correlation & $.703^{*}$ & 1 \\
\cline { 2 - 4 } & Sig. (2-tailed) & .023 & \\
\hline
\end{tabular}

*. Correlation is significant at the 0.05 level (2-tailed).

b. Listwise $\mathrm{N}=10$

Berdasarkan hasil pengujian pada tabel di atas diperoleh nilai korelasi sebesar 0,703 artinya Curent Ratio memiliki hubungan yang kuat terhadap Return On Asset.

\section{c. Analisis Koefisien Determinasi}

Analisis koefisien determinasi dimaksudkan untuk mengetahui besarnya persentase pengaruh dari variabel independen terhadap variabel dependen. Adapun hasil pengujian sebagai berikut:

Tabel 5. Hasil Pengujian Koefisien Determinasi Curent Ratio Terhadap Return On Asset.

Model Summary

\begin{tabular}{l|rr|r|r} 
& & \multicolumn{2}{c}{ Model Summary } & \multicolumn{2}{c}{$\begin{array}{c}\text { Adjusted R } \\
\text { Model }\end{array}$} & \multicolumn{2}{c}{ Error of the } \\
E & R Square & \multicolumn{2}{c}{ Square } & \multicolumn{2}{c}{ Estimate } \\
\hline 1 & $.703^{\mathrm{a}}$ & .494 & .431 & 1.06477 \\
\hline a. Predictors: (Constant), $\mathrm{CR}$ & &
\end{tabular}

Berdasarkan hasil pengujian pada tabel di atas diperoleh nilai determinasi sebesar 0,494 artinya Curent Ratio memiliki kontribusi pengaruh sebesar 49,4\% terhadap Return On Asset, sedangkan sisanya sebesar 50,6\% dipengaruhi faktor lain.

\section{d. Uji Hipotesis}

Pengujian hipotesis dengan uji t digunakan untuk mengetahui hipotesis mana yang diterima.

Rumusan hipotesis: Terdapat pengaruh yang signifikan Curent Ratio terhadap Return On Asset.

Tabel 6. Hasil Uji Hipotesis Curent Ratio Terhadap Return On Asset. Coefficients $^{\mathrm{a}}$

\begin{tabular}{|c|c|c|c|c|c|c|}
\hline \multirow{2}{*}{\multicolumn{2}{|c|}{ Model }} & \multicolumn{2}{|c|}{ Unstandardized Coefficients } & \multirow{2}{*}{$\begin{array}{c}\text { Standardized } \\
\text { Coefficients } \\
\text { Beta } \\
\end{array}$} & \multirow[b]{2}{*}{$\mathrm{t}$} & \multirow[b]{2}{*}{ Sig. } \\
\hline & & $\mathrm{B}$ & Std. Error & & & \\
\hline 1 & (Constant) & -8.392 & 6.023 & & -1.393 & .201 \\
\hline & $\mathrm{CR}$ & .072 & .026 & .703 & 2.794 & .023 \\
\hline
\end{tabular}


a. Dependent Variable: EPS

Berdasarkan hasil pengujian pada tabel di atas, diperoleh nilai t hitung $>\mathrm{t}$ tabel atau $(2,794>2,306)$, dengan demikian hipotesis yang diajukan bahwa terdapat pengaruh yang signifikan Curent Ratio terhadap Return On Asset diterima.

\section{Pembahasan Hasil Penelitian}

\section{Kondisi Nilai Variabel Curent Ratio}

Berdasarkan data empiris pada tabel di atas dan analisis data, variabel Curent Ratio dari data laporan keuangan selama 10 tahun diperoleh nilai rata-rata per tahun sebesar $234,38 \%$.

\section{Kondisi Nilai Variabel Return On Asset}

Berdasarkan data empiris pada tabel di atas dan analisis data, variabel Return On Asset dari data laporan keuangan selama 10 tahun diperoleh nilai rata-rata per tahun sebesar $8,40 \%$.

\section{Pengaruh Curent Ratio Terhadap Return On Asset}

Curent Ratio berpengaruh signifikan terhadap Return On Asset dengan persamaan regresi $\mathrm{Y}=-8,392+0,072 \mathrm{X}$, nilai korelasi sebesar 0,703 atau memiliki hubungan yang kuat dengan kontribusi pengaruh sebesar 49,4\%, sedangkan sisanya sebesar 50,6\% dipengaruhi oleh faktor lain yang tidak dilakukan penelitian. Pengujian hipotesis diperoleh nilai $\mathrm{t}$ hitung $>\mathrm{t}$ tabel atau $(2,794>2,306)$. Dengan demikian hipotesis yang diajukan bahwa terdapat berpengaruh yang signifikan antara Curent Ratio terhadap Return On Asset pada PT. Mayora, Tbk diterima.

\section{KESIMPULAN DAN SARAN}

\section{Kesimpulan}

a. Kondisi variabel Curent Ratio berdasar pada periode laporan keuangan 10 tahun diperoleh Curent Ratio rata-rata sebesar $234,38 \%$.

b. Kondisi variabel Return On Asset berdasar pada periode laporan keuangan 10 tahun diperoleh Curent Ratio rata-rata sebesar 8,40\%.

c. Curent Ratio berpengaruh signifikan terhadap Return On Asset dengan persamaan regresi $\mathrm{Y}=-8,392+0,072 \mathrm{X}$, nilai korelasi sebesar 0,703 atau kuat dan kontribusi pengaruh sebesar 49,4\% sedangkan sisanya sebesar 50,6\% dipengaruhi faktor lain. Uji hipotesis diperoleh nilai $t$ hitung $>\mathrm{t}$ tabel atau $(2,794>2,306)$.

\section{Saran}

Berdasarkan hasil penelitian yang sudah disimpulkan, maka penulis memberikan saran sebagai berikut:

a. Perusahaan harus mempertahankan posisi Current Ratio nya, karena dengan Current Ratio yang baik menunjukkan perusahaan dapat memenuhi kewajiban jangka pendeknya, tetapi Current Ratio yang terlalu tinggi pula dapat dikatakan tidak baik karena menandakan kelebihan uang kas atau aktiva lancar yang dibutuhkan

b. Perusahaan diharapkan dapat meningkatkan profitabiltas dengan cara melakukan survey lapangan terhadap para konsumen mengenai apa yang konsumen perlakukan, hal ini dimaksud untuk meningkatkan penjualan lebih baik lagi. 


\section{DAFTAR PUSTAKA}

Agus Harjito \& Martono, (2015) "Manajemen Keuangan" Yogyakarta: Penerbit Ekonisia.

Agus Sartono. (2016). "Manajemen Keuangan Toeri dan Aplikasi", Edisi keempat, Yogyakarta: Penerbit BPFE.

Algifari. (2015). "Analisis Regresi untuk Bisnis dan Ekonomi”. Yogyakarta: BPFE.

Arikunto, Suharsimi (2014). "Prosedur Penelitian Suatu Pendekatan Praktek". Jakarta: Rineka Cipta.

Bambang Riyanto, (2011). "Dasar-dasar Pembelanjaan Perusahaan". Edisi ke empat, Yogyakarta: BPFE.

Bintari, W. C., et al. (2019). Pelatihan Penyusunan Laporan Keuangan Secara Sederhana Pada Mahasiswa Fakultas Ekonomi Universitas Muhammadiyah Sorong. Abdimas: Papua Journal of Community Service, 1(2), 6-13.

Dumilah, R. et al (2021). Pengaruh Likuiditas Dan Profitabilitas Terhadap Struktur Modal Pada PT Mayora Indah, Tbk Periode 2010-2019. Jurnal Neraca Peradaban. 1(3) 237 245

Fahmi, Irham (2012), "Pengantar Manajemen Keuangan" Cetakan pertama. Bandung: Penerbit Alfabeta.

Imam Ghozali (2017). "Aplikasi Analisis Multivariate Dengan Program SPSS”. Edisi Kelima. Semarang: Badan Penerbit Undip.

Kasmir. (2012) "Pengantar Manajemen Keuangan”, Edisi Pertama, Cetakan kedua, Jakarta: Prenada Media.

Kharis, Ismu Fadli (2011). "Studi Mengenai Impulse Buying dalam Penjualan Online". Semarang : Skripsi Universitas Diponegoro

Martono dan Agus Harjito, (2011). "Manajemen Keuangan”, Jakarta: Penerbit Ekonisia.

Munawir (2010), “Analisis Laporan Keuangan”, Edisi Ke Empat, Yogyakarta: Penerbit Liberty.

Pangaribuan, H., et al. (2021). The Financial Perspective Study on Tax Avoidance. Budapest International Research and Critics Institute (BIRCI-Journal): Humanities and Social Sciences, 4(3), 4998-5009.

Sawir, (2003). "Analisis Kinerja Keuangan dan Perencanaan Keuangan Perusahaan", Cetakan ketiga, Jakarta: Penerbit PT. Gramedia Pustaka Utama.

Sugiyono (2017), "Metode Penelitian Administrasi : dilengkapi dengan Metode R \& D". Bandung: Alfabeta. 